\title{
Preoperative peripheral blood neutrophil count predicts long-term outcomes following hepatic resection for colorectal liver metastases
}

\author{
KOICHIRO HARUKI, HIROAKI SHIBA, YUKI FUJIWARA, KENEI FURUKAWA, TOMONORI IIDA, \\ MASAHISA OHKUMA, MASAICHI OGAWA, YUICHI ISHIDA, TAKEYUKI MISAWA and KATSUHIKO YANAGA
}

Department of Surgery, The Jikei University School of Medicine, Tokyo 105-8461, Japan

Received February 1, 2016; Accepted January 26, 2017

DOI: 10.3892/ol.2017.5873

\begin{abstract}
Preoperative systemic inflammatory response is associated with a poor long-term prognosis following resection surgery for malignant tumors. Several markers of systemic inflammation have been reported to be associated with the outcome; however, they have not currently been fully investigated. Therefore, the association between preoperative peripheral blood neutrophil count and oncological outcome following hepatic resection for colorectal liver metastasis (CRLM) was retrospectively investigated. The present study comprised 89 patients who had undergone hepatic resection for CRLM between January 2000 and March 2010. The association between preoperative peripheral blood neutrophil count and disease-free survival, in addition to overall survival, was investigated. In multivariate analysis, the presence of neoadjuvant chemotherapy $(\mathrm{P}=0.015)$, bilobar distribution $(\mathrm{P}=0.015)$ and neutrophil count $\geq 3,500 / \mu 1(\mathrm{P}=0.025)$ were independent and significant predictors of poor disease-free survival, while significant predictors of poor overall survival consisted of $>4$ lymph node metastases $(\mathrm{P}=0.001)$, neo-adjuvant chemotherapy $(\mathrm{P}=0.003)$, bilobar distribution $(\mathrm{P}=0.039)$ and neutrophil count $\geq 3,500 / \mu 1(\mathrm{P}=0.040)$. Additionally, tumor diameter $(\mathrm{P}=0.021)$ and monocyte count $(\mathrm{P}<0.0001)$ were observed to be significantly greater in the elevated neutrophil count group. In conclusion, preoperative peripheral blood neutrophil count may be an independent and significant indicator of poor long-term outcomes in patients with CRLM following hepatic resection.
\end{abstract}

\section{Introduction}

Colorectal cancer is a common type of malignancy and approximately $25 \%$ of individuals will have liver metastases at the

Correspondence to: Dr Koichiro Haruki, Department of Surgery, The Jikei University School of Medicine, 3-25-8 Nishi-Shinbashi, Minato-k, Tokyo 105-8461, Japan

E-mail: haruki@jikei.ac.jp

Key words: colorectal liver metastases, neutrophil, systemic inflammatory response, prognosis, hepatic resection time of the initial diagnosis. Furthermore, $40-50 \%$ of patients develop colorectal liver metastasis (CRLM) within three years of resection of the primary tumor (1). Hepatic resection is the most effective and potentially curative therapy for CRLM, with a reported five-year survival rate of $30-50 \%$ (2-4); the recent development of chemotherapeutic agents has further improved the outcome of patients with CRLM $(5,6)$. Therefore, assessment of prognostic predictors is important for the management of patients with CRLM.

Previously, several studies have indicated that systemic inflammatory response predicts cancer-specific survival in patients with cancer. The Glasgow prognostic score (GPS), which is calculated by the combination of serum C-reactive protein (CRP) and albumin concentrations, and the elevated preoperative neutrophil-to-lymphocyte ratio (NLR), have been revealed to predict cancer-specific survival (7-12). The previous study reported negative impact of GPS on post-operative complications following hepatic resection $(13,14)$, and the association between perioperative immunological response and prognosis subsequent to hepatic resection for HCC $(15,16)$ and CRLM (17). In the present study, the association between preoperative peripheral blood neutrophil count and disease-free, as well as overall survival, following elective hepatic resection for patients with CRLM was retrospectively investigated.

\section{Materials and methods}

Between January 2000 and December 2010, 96 patients with CRLM underwent hepatic resection at the Department of Surgery, Jikei University Hospital (Tokyo, Japan). Of these, seven patients were excluded, one patient for mortality due to a cardiovascular event, two patients due to lack of data and four patients who were lost to follow up, leaving the remaining 89 patients for this study. All patients underwent macroscopic curative resection for liver, lung and lymph node metastases. Liver resection was carried out prior to any other therapy treatments in order to avoid the possibility of liver failure. Neoadjuvant chemotherapy was administered when liver metastases were identified as unresectable or borderline resectable. Pre-operative chemotherapy was discontinued $>6$ weeks prior to hepatic resection in order to reduce liver 
injury and bone marrow suppression by chemotherapy. Generally, the extent of hepatic resection was determined based on the retention rate of indocyanine green at $15 \mathrm{~min}$ $\left(\mathrm{ICG}_{\mathrm{R} 15}\right)$ prior to surgery and hepatic reserve, as previously described by Miyagawa et al (18). A percutaneous transhepatic portal embolization was performed for patients with an estimated residual hepatic volume of $<30 \%$. Nomenclature of segments and types of operations follow the Brisbane 2000 terminology (19). The type of resection was classified into two groups: Major resection (resection of $\geq 3$ couinaud sub segments) and minor resection (resection $<3$ sub segments, or partial resection). The present study was approved by the Ethics Committee of The Jikei University School of Medicine (Tokyo, Japan).

Patient characteristics were classified into two groups for the Log-rank test and the Cox proportional hazards regression model as follows: Age $<65$ or $\geq 65$ years, number of regional lymph node metastases $<4$ or $\geq 4$, size of largest tumor $<50$ or $\geq 50 \mathrm{~mm}$, duration of operation $<300$ or $\geq 300 \mathrm{~min}$ and intraoperative blood loss $<1,000$ or $\geq 1,000 \mathrm{~g}$, according to previous studies (10-14). Using the mean or median of preoperative white blood cell subsets counts, they were classified as follows: Neutrophil $<3,500$ or $\geq 3,500 / \mu 1$, lymphocyte $<1,500$ or $\geq 1,500 / \mu 1$, monocyte counts $<500$ or $\geq 500 / \mu 1$.

Firstly, the association between clinical variables and disease-free or overall survival following hepatic resection by univariate and multivariate analysis was investigated. The following 13 variables were evaluated: Age, gender, number of regional lymph node metastases of primary colorectal cancer, synchronous or metachronous CRLM, status of neoadjuvant chemotherapy, tumor distribution, diameter of the largest tumor, type of resection, duration of operation, intraoperative blood loss and the neutrophil, lymphocyte, and monocyte count.

Subsequently, the correlation between neutrophil count and the patient characteristics was analyzed using the following 12 factors: Age, gender, number of regional lymph node metastases of primary colorectal cancer, synchronous or metachronous CRLM, status of neoadjuvant chemotherapy, tumor distribution, diameter of the largest tumor, type of resection, duration of operation, intraoperative blood loss and the lymphocyte and monocyte count.

Recurrence of colorectal cancer was defined as newly detected local, hepatic, lung or extrahepatic tumors by ultrasonography, computed tomography, or magnetic resonance imaging, with or without an increase in serum carcinoembryonic antigen or carbohydrate antigen 19-9 (CA 19-9). For recurrent liver metastasis, repeated hepatic resection, local ablation therapy or systemic chemotherapy was performed based primarily on the number, size and location of the recurrent liver tumors, in addition to hepatic functional reserve, including $\mathrm{ICG}_{\mathrm{R} 15}$, and remnant liver volume. For lung metastasis, limited partial lung resection or systemic chemotherapy was performed. For local recurrence, tumor resection, radiotherapy or systemic chemotherapy was performed. With regards to chemotherapy, 5-fluorouracil (5-Fu)-based chemotherapy was selected as adjuvant and/or neoadjuvant chemotherapy prior to 2003. Following 2004, the patients received infusional 5-Fu/1-leucovorin with oxaliplatin and/or infusional 5-Fu/1-leucovorin with irinotecan.
Statistical analysis. Data are expressed as the mean \pm standard deviation (SD). Analysis of disease-free and overall survival was performed using the Log-rank test. Univariate analysis was performed using the Mann-Whitney U-test and $\chi^{2}$ test. Multivariate analysis was performed using the Cox proportional regression model, incorporating all variables with $\mathrm{P}<0.05$ in the univariate analysis. These analyses were conducted using IBM ${ }^{\circledR}$ SPSS statistics version 20.0 (IBM SPSS, Armonk, NY, USA). $\mathrm{P}<0.05$ was considered to indicate a statistically significant difference.

\section{Results}

Patient characteristics. Patient characteristics are presented in Table I as the mean \pm SD, range or ratio. Preoperative neutrophil counts were $3,466.3 \pm 1,206.6 / \mu 1$ (mean \pm SD). Certain patients received neoadjuvant chemotherapy for liver resection (7/89).

Univariate and multivariate analysis of disease-free survival following hepatic resection and clinical variables. Table II presents the association between the clinical variables and disease-free survival following hepatic resection. In univariate analysis, disease-free survival was significantly poorer in patients with $>4$ lymph node metastases $(\mathrm{P}=0.018)$, presence of neoadjuvant chemotherapy $(\mathrm{P}=0.026)$, bilobar distribution $(\mathrm{P}=0.002)$ and neutrophil count $\geq 3,500 / \mu 1$ ( $\mathrm{P}=0.021$; Fig. 1A). In multivariate analysis, the presence of neoadjuvant chemotherapy $(\mathrm{P}=0.015)$, bilobar distribution $(\mathrm{P}=0.015)$ and neutrophil count $\geq 3,500 / \mu \mathrm{l}(\mathrm{P}=0.025)$, were independent and significant predictors of disease-free survival.

Univariate and multivariate analysis of overall survival following hepatic resection and clinical variables. Table III presents the association between the clinical variables and overall survival following hepatic resection. In univariate analysis, overall survival was significantly poorer in patients with $>4$ lymph node metastases $(\mathrm{P}<0.001)$, the presence of neoadjuvant chemotherapy $(\mathrm{P}=0.003)$, bilobar distribution $(\mathrm{P}=0.0007)$ and neutrophil count $\geq 3,500 / \mu 1 \quad(\mathrm{P}=0.029$; Fig. 1B). In multivariate analysis, $>4$ lymph node metastases $(\mathrm{P}=0.001)$, presence of neoadjuvant chemotherapy $(\mathrm{P}=0.003)$, bilobar distribution $(\mathrm{P}=0.039)$ and neutrophil count $\geq 3,500 / \mu 1(\mathrm{P}=0.040)$, were independent and significant predictors of overall survival.

Univariate analysis of clinical variables in association with the neutrophil count. Table IV presents the association between clinical variables and the neutrophil count. In univariate analysis, tumor diameter $(\mathrm{P}=0.021)$ and monocyte count $(\mathrm{P}<0.001)$ were significantly greater in the group of patients with an elevated neutrophil count. Synchronous CRLM $(\mathrm{P}=0.088)$ and intraoperative blood loss $(\mathrm{P}=0.065)$ tended to be greater in patients with elevated neutrophil count group; however, this was not statistically significant.

\section{Discussion}

Systemic inflammation has been reported to correlate with poorer cancer-specific survival in numerous types of 
Table I. Patient characteristics.

\begin{tabular}{lcc}
\hline Factor & Mean \pm SD or ratio & Range \\
\hline Age (years) & $64.0 \pm 9.8$ & $39-85$ \\
Gender (male:female) & $62: 27$ & \\
No. of lymph node metastases $(<4: \geq 4)$ & $67: 22$ & \\
Timing of tumor (synchronous:metachronous) & $41: 48$ & \\
Neoadjuvant chemotherapy (yes:no) & $7: 82$ & $10-200$ \\
Tumor distribution (unilobar:bilobar) & $22: 67$ & $85-867$ \\
Tumor size (mm) & $43.4 \pm 31.8$ & $25-5,485$ \\
Type of resection (major:minor) & $33: 56$ & $1,300-8,000$ \\
Duration of operation (min) & $349.8 \pm 144.9$ & $700-2,700$ \\
Intraoperative blood loss $(\mathrm{g})$ & $1,132.8 \pm 1,088.6$ & $0-600$ \\
Neutrophil count $(\mu \mathrm{l})$ & $3,466.3 \pm 1,206.6$ & \\
Lymphocyte count $(\mu \mathrm{l})$ & $1,514.6 \pm 443.0$ & $294.4 \pm 113.2$ \\
Monocyte count $(\mu \mathrm{l})$ & &
\end{tabular}

$\mathrm{SD}$, standard deviation.

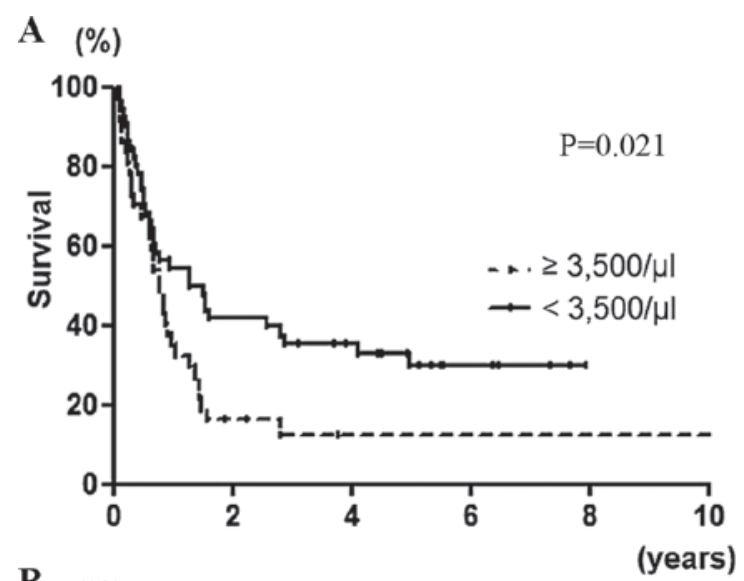

B $(\%)$

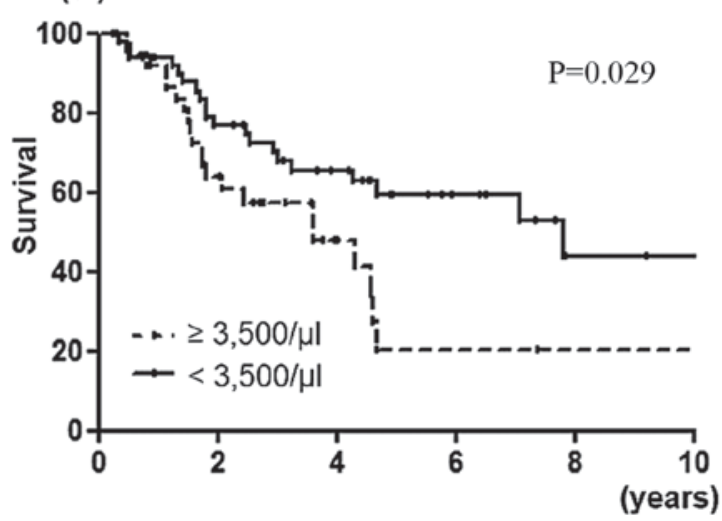

Figure 1. Kaplan-Meier curves of (A) disease-free and (B) overall surviva following hepatic resection for CRLM. Elevated neutrophil count $(\geq 3,500 / \mu 1)$ was significantly associated with the lowest disease-free survival $(\mathrm{P}=0.021)$ and overall survival rate $(\mathrm{P}=0.029)$. CRLM, colorectal liver metastasis.

cancer (7-12,20). Previous studies have demonstrated that the host inflammatory response to cancer and/or the systemic effects exerted by cancer cells leads to the upregulation of the inflammatory process, predisposing the cancer to proliferation and metastasis by the inhibition of apoptosis, promotion of angiogenesis and repair of DNA damage $(21,22)$. The presence of a systemic inflammatory response may be detected by the elevation of the CRP level and neutrophil count (7-12). Using these parameters, prognostic markers, including GPS and NLR, were reported to be associated with poor survival following hepatic resection for CRLM (9-11,23). In the present study disease-free and overall survival of patients with preoperative high neutrophil counts following elective hepatic resection for CRLM, was revealed to be significantly poorer by statistical analyses. The prognostic value of NLR in the present study cohort was also investigated; however, NLR was not a significant predictor of the overall survival $(\mathrm{P}=0.193$, data not presented). This result indicates that neutrophil counts may themselves be an inflammatory and prognostic marker. Neal et al (24) demonstrated that the neutrophil count had a greater predictive value on long-term outcomes compared with NLR, when the multivariate Cox proportional regression model analyzed factors.

Inflammatory status represents a response process to detection of CRLM (25). In the present study, tumor size was larger in patients with higher neutrophil counts. These results indicate that tumor invasion or expansion elicits inflammation in the microenvironment. Neutrophils contribute to continuous angiogenic stimulation, including the release of endothelial growth factor (26). This condition may accelerate the growth of cancer cells or micro-metastases (27). Additionally, systemic inflammation also induces the suppression of antitumor immunity by recruitment of regulatory $\mathrm{T}$ cells and activation of cytokines (25). Preoperative systemic inflammation and an immunosuppressive state may increase the risk of postoperative infectious complications, which influence long-term outcomes in patients with CRLM $(24,28)$.

In the present study, neoadjuvant chemotherapy demonstrated a negative impact on long-term outcomes following hepatic resection for CRLM. Neoadjuvant chemotherapy prior to hepatic resection in patients with resectable CRLM 
Table II. Univariate and multivariate analysis of clinical variables in association with disease-free survival following hepatic resection.

\begin{tabular}{|c|c|c|c|c|c|}
\hline \multirow[b]{2}{*}{ Factor } & \multirow[b]{2}{*}{$\mathrm{N}$} & \multicolumn{2}{|c|}{ Univariate analysis } & \multicolumn{2}{|c|}{ Multivariate analysis } \\
\hline & & Hazard ratio $(95 \% \mathrm{CI})$ & P-value & Hazard ratio $(95 \% \mathrm{CI})$ & P-value \\
\hline Age (years) & & & 0.192 & & \\
\hline$\geq 65$ & 46 & 1.382 & & & \\
\hline$<65$ & 43 & $(0.850-2.246)$ & & & \\
\hline Gender & & & 0.913 & & \\
\hline Male & 62 & 1.030 & & & \\
\hline Female & 27 & $(0.606-1.751)$ & & & \\
\hline No. of lymph node metastases & & & $0.018^{\mathrm{a}}$ & & 0.079 \\
\hline$\geq 4$ & 22 & 2.107 & & 1.656 & \\
\hline$<4$ & 67 & $(1.133-3.917)$ & & $(0.947-2,895)$ & \\
\hline Timing of tumor & & & 0.200 & & \\
\hline Synchronous & 41 & 1.381 & & & \\
\hline Metachronous & 48 & $(0.843-2.260)$ & & & \\
\hline Neoadjuvant chemotherapy & & & $0.026^{\mathrm{a}}$ & & $0.015^{\mathrm{a}}$ \\
\hline Yes & 7 & 4.170 & & 3.155 & \\
\hline No & 82 & $(1.182-14.71)$ & & $(1.249-7.966)$ & \\
\hline Tumor distribution & & & $0.002^{\mathrm{a}}$ & & $0.015^{\mathrm{a}}$ \\
\hline Bilobar & 22 & 2.770 & & 1.961 & \\
\hline Unilobar & 67 & $(1.458-5.265)$ & & $(1.143-3.366)$ & \\
\hline Tumor size (mm) & & & 0.402 & & \\
\hline$\geq 50$ & 24 & 1.272 & & & \\
\hline$<50$ & 65 & $(0.724-2.234)$ & & & \\
\hline Type of resection & & & 0.818 & & \\
\hline Major & 33 & 1.061 & & & \\
\hline Minor & 56 & $(0.639-1.762)$ & & & \\
\hline Duration of operation (min) & & & 0.397 & & \\
\hline$\geq 300$ & 55 & 1.238 & & & \\
\hline$<300$ & 34 & $(0.756-2.028)$ & & & \\
\hline Intraoperative blood loss (g) & & & 0.875 & & \\
\hline$\geq 1,000$ & 39 & 1.040 & & & \\
\hline$<1,000$ & 50 & $(0.639-1.691)$ & & & \\
\hline Neutrophil count $(\mu 1)$ & & & $0.021^{\mathrm{a}}$ & & $0.025^{\mathrm{a}}$ \\
\hline$\geq 3,500$ & 37 & 1.827 & & 1.838 & \\
\hline$<3,500$ & 52 & $(1.093-3.052)$ & & $(1.087-3.134)$ & \\
\hline Lymphocyte count $(\mu \mathrm{l})$ & & & 0.805 & & \\
\hline$\geq 1,500$ & 49 & 1.063 & & & \\
\hline$<1,500$ & 40 & $(0.653-1.730)$ & & & \\
\hline Monocyte count $(\mu \mathrm{l})$ & & & 0.899 & & \\
\hline$\geq 300$ & 57 & 1.143 & & & \\
\hline$<300$ & 32 & $(0.694-1.883)$ & & & \\
\hline
\end{tabular}

${ }^{\mathrm{a}} \mathrm{P}<0.05 ; \mathrm{CI}$, confidence interval.

may facilitate the resectability of liver lesions and treat occult metastasis; however, it may also lead to hepatic parenchymal injury, which may increase morbidity and mortality following surgery $(29,30)$. There are conflicting opinions over the oncological benefit of this practice in patients who may already be suitable for a curative hepatic resection $(31,32)$. Additionally, in the present study patients treated with neoadjuvant chemotherapy were limited and 
Table III. Univariate and multivariate analysis of clinical variables in association with overall survival following hepatic resection.

\begin{tabular}{|c|c|c|c|c|c|}
\hline \multirow[b]{2}{*}{ Factor } & \multirow[b]{2}{*}{$\mathrm{N}$} & \multicolumn{2}{|c|}{ Univariate analysis } & \multicolumn{2}{|c|}{ Multivariate analysis } \\
\hline & & Hazard ratio $(95 \% \mathrm{CI})$ & P-value & Hazard ratio $(95 \% \mathrm{CI})$ & P-value \\
\hline Age (years) & & & 0.947 & & \\
\hline$\geq 65$ & 46 & 1.021 & & & \\
\hline$<65$ & 43 & $(0.552-1.890)$ & & & \\
\hline Gender & & & 0.885 & & \\
\hline Male & 62 & 0.952 & & & \\
\hline Female & 27 & $(0.488-1.856)$ & & & \\
\hline No. of lymph node metastases & & & $<0.001^{\mathrm{a}}$ & & $0.001^{\mathrm{a}}$ \\
\hline$\geq 4$ & 22 & 4.311 & & 3.023 & \\
\hline$<4$ & 67 & $(1.968-9.447)$ & & $(1.585-5.765)$ & \\
\hline Timing of tumor & & & 0.423 & & \\
\hline Synchronous & 41 & 1.287 & & & \\
\hline Metachronous & 48 & $(0.694-2.389)$ & & & \\
\hline Neoadjuvant chemotherapy & & & $0.003^{\mathrm{a}}$ & & $0.003^{\mathrm{a}}$ \\
\hline Yes & 7 & 12.46 & & 5.058 & \\
\hline No & 82 & $(2.370-65.60)$ & & $(1.748-14.436)$ & \\
\hline Tumor distribution & & & $0.007^{\mathrm{a}}$ & & $0.039^{\mathrm{a}}$ \\
\hline Bilobar & 22 & 2.093 & & 2.021 & \\
\hline Unilobar & 67 & $(1.337-6.304)$ & & $(1.035-3.944)$ & \\
\hline Tumor size (mm) & & & 0.275 & & \\
\hline$\geq 50$ & 24 & 1.510 & & & \\
\hline$<50$ & 65 & $(0.721-3.160)$ & & & \\
\hline Type of resection & & & 0.884 & & \\
\hline Major & 33 & 1.049 & & & \\
\hline Minor & 56 & $(0.556-1.977)$ & & & \\
\hline Duration of operation (min) & & & 0.373 & & \\
\hline$\geq 300$ & 55 & 1.335 & & & \\
\hline$<300$ & 34 & $(0.707-2.522)$ & & & \\
\hline Intraoperative blood loss (g) & & & 0.185 & & \\
\hline$\geq 1,000$ & 39 & 1.527 & & & \\
\hline$<1,000$ & 50 & $(0.817-2.853)$ & & & \\
\hline Neutrophil count $(\mu 1)$ & & & $0.029^{\mathrm{a}}$ & & $0.040^{\mathrm{a}}$ \\
\hline$\geq 3,500$ & 37 & 2.066 & & 2.016 & \\
\hline$<3,500$ & 52 & $(1.078-3.960)$ & & $(1.031-3.941)$ & \\
\hline Lymphocyte count $(\mu 1)$ & & & 0.660 & & \\
\hline$\geq 1,500$ & 49 & 1.149 & & & \\
\hline$<1,500$ & 40 & $(0.620-2.130)$ & & & \\
\hline Monocyte count $(\mu 1)$ & & & 0.822 & & \\
\hline$\geq 300$ & 57 & 0.930 & & & \\
\hline$<300$ & 32 & $(0.492-1.757)$ & & & \\
\hline
\end{tabular}

${ }^{\mathrm{a}} \mathrm{P}<0.05 ; \mathrm{CI}$, confidence interval.

had a more aggressive disease, including bilobar distribution ( $\mathrm{P}=0.038$, data not presented), compared with patients without neo-adjuvant chemotherapy on initial presentation, as liver resection had priority over other therapies at Jikei University Hospital.
In summary, preoperative elevation of the peripheral neutrophil count is an independent risk factor for disease-free as well as overall survival. Prevention of systemic inflammatory response may improve perioperative outcomes and long-term survival following resection of malignant tumors. Several 
Table IV. Univariate analysis of clinical variables in association with preoperative neutrophil counts.

\begin{tabular}{lccr}
\hline & & Neutrophil count \\
\cline { 2 - 4 } Factor & $<3,500 / \mu 1(\mathrm{n}=52)$ & $\geq 3,500 / \mu 1(\mathrm{n}=37)$ & P-value \\
\hline Age (years) & $63.8 \pm 8.9$ & $64.2 \pm 11.1$ & 0.723 \\
Gender (male:female) & $34: 18$ & $28: 9$ & 0.298 \\
No. of lymph node metastases $(<4: \geq 4)$ & $42: 10$ & $27: 10$ & 0.155 \\
Timing of tumor (synchronous:metachronous) & $20: 32$ & $21: 16$ & 0.088 \\
Neoadjuvant chemotherapy (yes:no) & $6: 46$ & $1: 36$ & 0.127 \\
Tumor distribution (unilobar:bilobar) & $40: 12$ & $27: 10$ & 0.670 \\
Tumor size (mm) & $35.4 \pm 19.4$ & $54.5 \pm 41.6$ & 0.021 \\
Type of resection (major:minor) & $20: 32$ & $13: 24$ & 0.749 \\
Duration of operation (min) & $341.3 \pm 142.7$ & $361.8 \pm 149.0$ & 0.524 \\
Intraoperative blood loss $(\mathrm{g})$ & $939.1 \pm 962.3$ & $1,405.0 \pm 1,206.1$ & 0.065 \\
Lymphocyte count $(/ \mu 1)$ & $1,526.9 \pm 422.0$ & $1,497.3 \pm 476.4$ & 0.789 \\
Monocyte count $(/ \mu 1)$ & $251.9 \pm 101.9$ & $354.1 \pm 101.6$ & $<0.001^{\mathrm{a}}$ \\
\hline
\end{tabular}

${ }^{\mathrm{a}} \mathrm{P}<0.05$.

therapeutic agents targeting the inflammatory response are undergoing clinical trials (33). Further investigation to clarify the association between the immunosuppressive mechanisms induced by systemic inflammation and tumor progression is important in order to improve the therapeutic outcome of oncological surgery. In conclusion, preoperative peripheral blood neutrophil count is an independent and significant indicator of long-term outcomes in patients with CRLM following hepatic resection.

\section{References}

1. O'Reilly DA and Poston GJ: Colorectal liver metastases: Current and future perspectives. Future Oncol 2: 525-531, 2006.

2. Fong Y, Fortner J, Sun RL, Brennan MF and Blumgart LH: Clinical score for predicting recurrence after hepatic resection for metastatic colorectal cancer: Analysis of 1001 consecutive cases. Ann Surg 230: 309-321, 1999.

3. Malik HZ, Prasad KR, Halazun KJ, Aldoori A, Al-Mukhtar A, Gomez D, Lodge JP and Toogood GJ: Preoperative prognostic score for predicting survival after hepatic resection for colorectal liver metastases. Ann Surg 246: 806-814, 2007.

4. Simmonds PC, Primrose JN, Colquitt JL, Garden OJ, Poston GJ and Rees M: Surgical resection of hepatic metastases from colorectal cancer: A systematic review of published studies. Br J Cancer 94: 982-999, 2006.

5. Loupakis F, Cremolini C, Masi G, Lonardi S, Zagonel V, Salvatore L, Cortesi E, Tomasello G, Ronzoni M, Spadi R, et al: Initial therapy with FOLFOXIRI and bevacizumab for metastatic colorectal cancer. N Engl J Med 371: 1609-1618, 2014.

6. Simkens LH, van Tinteren H, May A, ten Tije AJ, Creemers GJ, Loosveld OJ, de Jongh FE, Erdkamp FL, Erjavec Z, van der Torren AM, et al: Maintenance treatment with capecitabine and bevacizumab in metastatic colorectal cancer (CAIRO3): A phase 3 randomised controlled trial of the Dutch Colorectal Cancer Group. Lancet 385: 1843-1852, 2015.

7. Proctor MJ, Morrison DS, Talwar D, Balmer SM, O'Reilly DS, Foulis AK, Horgan PG and McMillan DC: An inflammation-based prognostic score (mGPS) predicts cancer survival independent of tumor site: A Glasow inflammation outcome study. Br J Cancer 104: 726-734, 2011.

8. McMillan DC: An inflammation-based prognostic score and its role in the nutrition-based management of patients with cancer. Proc Nutr Soc 67: 257-262, 2008.
9. Halazun KJ, Aldoori A, Malik HZ, Al-Mukhtar A, Prasad KR, Toogood GJ and Lodge JP: Elevated preoperative neutrophil to lymphocyte ratio predicts survival following hepatic resection for colorectal liver metastases. Eur J Surg Oncol 34: 55-60, 2008.

10. Giakoustidis A, Neofytou K, Khan AZ and Mudan S: Neutrophil to lymphocyte ratio predicts pattern of recurrence in patients undergoing liver resection for colorectal liver metastasis and thus the overall survival. J Surg Oncol 111: 445-450, 2015.

11. Gomez D, Morris-Stiff G, Wyatt J, Toogood GJ, Lodge JP and Prasad KR: Surgical technique and systemic inflammation influences long-term disease-free survival following hepatic resection for colorectal metastasis. J Surg Oncol 98: 371-376, 2008.

12. Mano Y, Shirabe K, Yamashita Y, Harimoto N, Tsujita E, Takeishi K, Aishima S, Ikegami T, Yoshizumi T, Yamanaka T and Maehara Y: Preoperative neutrophil-to-lymphocyte ratio is a predictor of survival after hepatectomy for hepatocellular carcinoma: A retrospective analysis. Ann Surg 258: 301-305, 2013.

13. Fujiwara Y, Shiba H, Furukawa K, Iida T, Haruki K, Gocho T, Wakiyama S, Hirohara S, Ishida Y, Misawa T, et al: Glasgow prognostic score is related to blood transfusion requirements and post-operative complications in hepatic resection for hepatocellular carcinoma. Anticancer Res 30: 5129-5136, 2010.

14. Haruki K, Shiba H, Fujiwara Y, Furukawa K, Wakiyama S, Ogawa M, Ishida Y, Misawa T and Yanaga K: Negative impact of surgical site infection on long-term outcomes after hepatic resection for colorectal liver metastases. Anticancer Res 33: 1697-1703, 2013.

15. Fujiwara Y, Shiba H, Furukawa K, Iida T, Sakamoto T, Gocho T, Wakiyama S, Hirohara S, Ishida Y, Misawa T, et al: Perioperative change in white blood cell count predicts outcome of hepatic resection for hepatocellular carcinoma. J Hepatobiliary Pancreat Sci 17: 892-897, 2010.

16. Shiba H, Furukawa K, Fujiwara Y, Futagawa Y, Haruki K, Wakiyama S, Ishida Y, Misawa T and Yanaga K: Postoperative peak serum C-reactive protein predicts outcome of hepatic resection for hepatocellular carcinoma. Anticancer Res 33: 705-709, 2013.

17. Haruki K, Shiba H, Fujiwara Y, Furukawa K, Wakiyama S, Ogawa M, Ishida Y, Misawa T and Yanaga K: Perioperative change in peripheral blood monocyte count may predict prognosis in patients with colorectal liver metastasis after hepatic resection. J Surg Oncol 106: 31-35, 2012.

18. Miyagawa S, Makuuchi M, Kawasaki S and Kakazu T: Criteria for safe hepatic resection. Am J Surg 169: 589-594, 1995.

19. Strasberg SM: Nomenclature of hepatic anatomy and resections: A review of the Brisbane 2000 system. J Hepatobiliary Pancreat Surg 12: 351-355, 2005.

20. Coussens LM and Werb Z: Inflammation and cancer. Nature 420: 860-867, 2002. 
21. Jaiswal M, LaRusso NF, Burgart LJ and Gores GJ: Inflammatory cytokines induce DNA repair in cholangiocarcinoma cells by a nitricoxide-dependent mechanism. Cancer Res 60: 184-190, 2000.

22. McMillan DC, Canna K and McArdle CS: Systemic inflammatory response predicts survival following curative resection of colorectal cancer. Br J Surg 90: 215-219, 2003.

23. Kobayashi T, Teruya M, Kishiki T, Endo D, Takenaka Y, Miki K, Kobayashi K and Morita K: Elevated C-reactive protein and hypoalbuminemia measured before resection of colorectal live rmetastases predict postoperative survival. Dig Surg 27: 285-290, 2010.

24. Neal CP, Mann CD, Garcea G, Briggs CD, Dennison AR and Berry DP: Preoperative systemic inflammation and infectious complications after resection of colorectal liver metastases. Arch Surg 146: 471-478, 2011.

25. Grivennikov SI, Greten FR and Karin M: Immunity, inflammation, and cancer. Cell 140: 883-899, 2010.

26. Taichman NS, Young S, Cruchley AT, Taylor P and Paleolog E: Human neutrophils secrete vascular endothelial growth factor. J Leukoc Biol 62: 397-400, 1997.

27. Maniwa Y, Okada M, Ishii N and Kiyooka K: Vascular endothelial growth factor increased by pulmonary surgery accelerates the growth of micrometastases in metastatic lung cancer. Chest 114: 1668-1675, 1998

28. Farid SG, Aldouri A, Morris-Stiff G, Khan AZ, Toogood GJ, Lodge JP and Prasad KR: Correlation between postoperative infective complications and long-term outcomes after hepatic resection for colorectal liver metastasis. Ann Surg 251: 91-100, 2010 .
29. Nakano H, Oussoultzoglou E, Rosso E, Casnedi S, Chenard-Neu MP, Dufour P, Bachellier P and Jaeck D: Sinusoidal injury increases morbidity after major hepatectomy in patients with colorectal liver metastases receiving preoperative chemotherapy. Ann Surg 247: 118-124, 2008.

30. Vauthey JN, Pawlik TM, Ribero D, Wu TT, Zorzi D, Hoff PM, Xiong HQ, Eng C, Lauwers GY, Mino-Kenudson M, et al: Chemotherapy regimen predicts steatohepatitis and an increase in 90-day mortality after surgery for hepatic colorectal metastases. J Clin Oncol 24: 2065-2072, 2006.

31. Viganò L, Capussotti L, De Rosa G, De Saussure WO, Mentha G and Rubbia-Brandt L: Liver resection for colorectal metastases after chemotherapy: Impact of chemotherapy-related liver injuries, pathological tumor response, and micrometastases on long-term survival. Ann Surg 258: 731-742, 2013.

32. Leal JN, Bressan AK, Vachharajani N, Gonen M, Kingham TP, D'Angelica MI, Allen PJ, DeMatteo RP, Doyle MB, Bathe OF, et al: Time-to-surgery and survival outcomes in resectable colorectal liver metastases: A multi-institutional evaluation. J Am Coll Surg 222: 766-779, 2016.

33. Balkwill $\mathrm{F}$ and Mantovani A: Cancer and inflammation: Implications for pharmacology and therapeutics. Clin Pharmacol Ther 87: 401-406, 2010. 